\title{
Hacia una fundamentación de la ecoética
}

\author{
Francisco Javier LÓPEZ DE GOICOECHEA ZABALA \\ Departamento de Derecho Eclesiástico del Estado \\ Universidad Complutense de Madrid \\ fjlopezg@der.ucm.es
}

Recibido: 5 de noviembre de 2014

Enviado a evaluar: 8 de noviembre de 2014

Aceptado: 17 de noviembre de 2014

\section{RESUMEN}

La ética ambiental o Ecoética, nace como respuesta a la degradación del entorno de la vida humana en nuestros tiempos, tomando como referencia los valores y principios de una ética aplicada a diferentes sectores profesionales que inciden de manera directa con su actividad en el medio. Intentamos, así, fundamentar una ética medioambiental desde los mismos presupuestos que cualquier ética aplicada, desde la propia génesis de nuestra conciencia moral individual hasta la particularidad de la pluralidad de sectores a los que debe dirigirse.

Palabras clave: Ética, principios, conciencia, deontología.

\section{Towards a foundation of ecoethics}

\begin{abstract}
Environmental or ecoethics, ethics developed in response to environmental degradation of human life in our times, with reference to the values and principles of professional ethics applied to different sectors directly affect its activity in the medium. Try, so base an environmental ethic from the same assumptions applied to any ethical, from the genesis of our individual conscience to the particularity of the plurality of sectors to be targeted.
\end{abstract}

Key words: Ethics, principles, conscience, deontology.

Vers une base de ecoethics

\section{RÉSUMÉ}

L'environnement ou ecoethics, éthique développés en réponse à la dégradation de l'environnement de la vie humaine à notre époque, en référence aux valeurs et principes de l'éthique professionnelle appliqués aux différents secteurs affecter directement son activité dans le milieu. Essayez, si fonder une éthique de l'environnement à partir des mêmes hypothèses appliquées à toute éthique, de la genèse de notre conscience individuelle à la particularité de la pluralité de secteurs à cibler.

Mots clés: Ethique, de principes, de conscience, de l'éthique. 


\section{INTRODUCCIÓN: EL ASNO DE BURIDÁN}

Hace más de cuarenta años que V.R.Potter publicó un famoso artículo donde dio nombre a un nuevo concepto ético denominado Bioética. Para él, se trataba de dar cuenta desde la ética o filosofía moral de las complejas decisiones que en nuestro mundo actual debíamos tomar sobre la vida del planeta, es decir, sobre nuestra vida humana y la de nuestro entorno. Ahí pudiera parecer que comienza un discurso ético sobre la vida en un sentido genérico, tomando como referencia a la vida humana y a la vida que nos rodea y conforma nuestro medio.

Sin embargo, la urgencia en tratar las decisiones a tomar en el cada vez más complejo mundo de la medicina humana y, por tanto, en el terreno de las difíciles implicaciones en el medio hospitalario y sus relaciones médico-paciente, hizo que aquella Bioética de Potter culminara por servir de guía y reflexión a la ética médica aplicada y a la toma de decisiones en el campo de la medicina hospitalaria, en exclusiva.

El olvido de que nuestra vida humana se encuentra imbricada en un entorno igualmente vital y delicado, hizo que la reflexión ética y moral sobre nuestra incidencia sobre el entorno ambiental quedara relegada. De nuevo el olvido de la physis que la Filosofía ha reclamado durante siglos, surgió con fuerza ante acontecimientos que nuestro mundo contemporáneo contempló con estupor y preocupación: desde el descenso en los niveles de ozono de nuestra atmósfera, hasta el denominado efecto invernadero, pasando por catástrofes ecológicas como la de la central rusa de Chernóbil, hicieron que aquella vieja reflexión de Potter sobre una ética de la vida del planeta cobrara de nuevo sentido y urgencia intelectual y práctica. De nuevo surgía aquella precipitada pregunta que los filósofos de la Ilustración no supieron responder ante el terremoto de Lisboa del año 1776, que parecía nos dejaba indefensos y sin solución alguna por parte de aquella razón de los modernos, razón científica y filosófica, cuya única respuesta parecía ser el designio de los nuevos tiempos y su sentido el sinsentido del progreso humano.

Nadie duda ya de que asistimos, en este umbral del nuevo milenio, a un cambio radical de lo que Khun llamó paradigmas, teniendo como horizonte inmediato la acomodación de todas nuestras estructuras culturales, científicas, éticas y jurídicas al nuevo paradigma imperante que no es otro que el de denominada tecno-ciencia. Superada la ciencia-ficción, asistimos perplejos al desarrollo incesante de una serie de técnicas aplicadas, sin saber muy bien qué decir o, en el peor de los casos, siguiendo el rastro de aquel asno de Buridán que por no mirar a su entorno murió de hambre entre campos de cebada.

Pues bien, si no queremos seguir los pasos del asnado y nihilista animal, debemos intentar una reflexión a fondo y de fondo sobre todos aquellos principios que hasta ahora venían siendo del común de las reflexiones éticas, pero que desde este momento han sido puestas en cuestión, cuando no totalmente desterradas del reino de la tecno-ciencia. Y no se trata, en este caso, ni de poner puertas al campo, cosa me temo también bastante nihilista, ni de hacer profética antes que ética. No, se trata simplemente de intentar un acercamiento ético $y$, finalmente, jurídico a una materia 
que ha recibido el impacto que acompaña toda ruptura del paradigma imperante. Por eso nos queremos preguntar por el sentido y fundamento de lo que suele denominarse Ecoética, precisamente para diferenciarla de la Bioética aplicada al mundo exclusivo de la medicina actual. Es decir, ¿tiene sentido hablar de una ética ambiental, o mejor, de una ética aplicada al medio ambiente? O lo que es lo mismo, ¿cabe la Ecoética? ${ }^{1}$.

\section{LA GÉNESIS DE LA CONCIENCIA MORAL}

Comenzamos diferenciando entre dos conceptos que suelen parecer sinónimos o, cuando menos, complementarios. Por un lado, entendemos lo moral como el ámbito propio de la conciencia individual que a través de diferentes factores, desde los puramente instintivos hasta los educativos y existenciales, constituye en cada uno de nosotros una serie de valores y deberes que nos hacen dar cuenta de nuestras decisiones y de las que nos afectan de los demás. Por otro lado, cuando nuestra conciencia moral individual sale al encuentro con los demás, enfrentándose al marco social de convivencia y a la lógica pluralidad de dimensiones individuales valorativas, en ese encuentro intersubjetivo es cuando aparece la ética y la necesidad de establecer criterios comunes de convivencia, a través de un marco común de deberes compartidos que todos podamos cumplir de manera universalizable.

El objeto material de la ética es la vida en cuanto êthos o forma de ser, que cada cual se va haciendo y apropiando. Si nos acercamos al ser humano y al papel que puede desempeñar lo moral en su devenir como hombre, incluso bajo el impulso tecnológico, debemos volver a la definición de los seres humanos como seres inteligentes que necesitan justificar no sólo sus actos morales, sino también sus presupuestos. Ahora bien, ¿cómo surge la conciencia moral en el ser humano? Son muchas las respuestas que se han dado al respecto. Siguiendo a Rubio Carracedo podemos ver que quizá la primera respuesta proviene del mundo griego y, en concreto, de la filosofía platónico-aristotélica, que efectúan un planteamiento innatista de la obligación moral; es decir, como elaborarán los estoicos, existe en el hombre, como en los animales, un instinto originario de autoprotección que nos lleva a evaluar lo que es conveniente y lo que no lo es ${ }^{2}$. Se trata de una fundamentación naturalista de la moral en la que el deber natural se deriva inmediatamente de un derecho natural en cuanto base y norma de los derechos positivos. Ya el cristianismo adoptó como

\footnotetext{
${ }^{1}$ Para una aproximación a una ética aplicada al medio ambiente, Vid. CORTINA, A., Las fronteras de la persona. El valor de los animales, la dignidad de la persona, Madrid 2009; GAFO, J., "Ecoética", en 10 palabras clave en Ecologia, Estells 1999; GÓMEZ HERAS, J.M., Ética del medio ambiente. Problema, perspectiva, historia, Madrid 1997; GRACIA, D., Fundamentos de Bioética, Madrid 1989; KÜNG, H., Una ética mundial para la economía y la política, Madrid 1999; LEOPOLD, A, Una ética de la tierra, Madrid 2000; POTTER, V.R., Global Bioethics, Michigan 1998; SINGER, P., Ética práctica, Barcelona 1984; TAYLOR, W., Respect for Nature: a theory of enviroment ethics, Princeton 1986.

${ }^{2}$ Cf.RUBIO CARRACEDO, J., El hombre y la ética, Anthropos, Barcelona 1987 (cap.IV).
} 
fundamento último la teoría de la ley divina, en tanto que ley revelada y eterna, en la que el hombre participa a través de la razón.

La ruptura de los enfoques innatistas tradicionales fue protagonizada por Hobbes en el contexto de la filosofía anglosajona y por Rousseau en el ámbito continental, entendiendo que la obligación moral se produce conjuntamente con la génesis de la propia sociedad, a partir de un pacto o convención social. Por tanto, se rompe el innatismo individual para dejar paso al contractualismo que ha llegado hasta nuestros días a través de los aprioris kantianos, del utilitarismo de Bentham, del idealismo alemán, de los recientes neocontractualismos de autores como Rawls o del consensualismo dialógico de Habermas o Apel.

Un tercer planteamiento provino del existencialismo, dividiendo en estadios o modalidades la propia existencia humana. Así, Kierkegaard nos describe los diferentes estadios o etapas por las cuales debe evolucionar el ser moral del hombre, concluyendo que el estadio de la vida ética proviene de dos componentes esenciales en el ser humano: su afirmación incondicional de sí mismo; y la angustia propia del fracaso inevitable de dicha afirmación.

El siguiente paso lo dio Freud al plantear la génesis de la moral adecuada a los descubrimientos psicoanalíticos. Por tanto su planteamiento está estrechamente relacionado con la biogenética fundamental. Para Freud en el principio fue el Ello, haz de instintos libidinosos y agresivos que dominan la vida infantil. Aparece entonces el Yo como una instancia autónoma a partir de cierta racionalización del Ello, regida primordialmente por el principio de realidad, es decir, por la búsqueda de un equilibrio entre las ciegas pasiones del Ello, la realidad exterior y la presión que ejerce el tercer momento del psiquismo moral: el Super-Yo. Al final, sólo el individuo que alcance una verdadera madurez del Yo, ajena al complejo de Edipo y al complejo de castración ante el dominio paterno, podrá desarrollar una moralidad autónoma, alejada de creencias que no son sino proyecciones del Super-Yo.

Por su parte Piaget, analiza cómo los individuos se adaptan a las reglas existentes pasando por una primera fase individual y manipulativa de dichas reglas; una segunda fase egocéntrica; una tercera cooperativa; y una cuarta codificadora de las reglas. De aquí deduce tres tipos de reglas morales: un primer tipo de reglas puramente motrices; un segundo tipo de reglas coercitivas; y un tercer tipo de reglas racionales. Estos tipos de reglas morales nos sirven para confirmar el tránsito de los meros modelos morales a los valores y normas abstractas, es decir, a la elaboración personal de tales pautas de comportamiento que conlleva una cierta madurez intelectual.

Finalmente, ha sido Kohlberg quien ha definido con más precisión los diferentes estadios en el desarrollo moral humano, partiendo de los propios estadios del desarrollo cognitivo. Así, articula tres fases claramente definidas en el desarrollo moral humano: una primera fase premoral, donde los valores morales residen en sucesos externos, cuasi-físicos, más que en personas; una segunda etapa convencional, en la que los valores morales residen en realizar buenos o malo roles en relación con las expectativas de los demás; $y$, finalmente, una tercera fase de principios morales personalmente aceptados, donde los valores residen en la conformidad del yo con normas, derechos y deberes compartidos con los demás. Posteriormente, el propio 
Kohlberg ha matizado y desarrollado cada una de estas fases, pero nos vale como esquema general de evolución moral humana.

De este breve desarrollo de las diferentes teorías sobre la conformación de nuestra actividad moral, es decir, sobre el desarrollo de nuestra conciencia moral individual, podríamos añadir que para que surja en ella una percepción ecoética parece que la clave estará en aunar el reclamo instintivo de nuestra supervivencia como especie, junto a la actividad educadora que debe intentar devolvernos aquella consideración de los antiguos de que formamos parte de un Kosmos integral, difícilmente escindible en dos realidades contrapuestas. Es decir, una educación que nos permita reconocernos en nuestro entorno, no a la manera cartesiana de objetivar lo que nos rodea, res extensa, desde nuestra superioridad ontológica, res cogitans, sino precisamente superando esta escisión cartesiana y entendernos como parte de una misma realidad de la que tenemos que responder, responsabilidad, y a la que debemos una respuesta ética de nuestras acciones, intersubjetividad.

\section{CONCIENCIA MORAL Y HORIZONTE TECNO-CIENTÍFICO}

Vistas las diferentes teorías sobre la evolución moral del ser humano, debemos plantearnos ahora con Javier Muguerza si queda todavía un lugar para la ética en el marco del horizonte cultural actual, impregnado fundamentalmente por la constante científica y sus aplicaciones tecnológicas ${ }^{3}$. Y no es fácil salir airosos de semejante planteamiento teniendo en cuenta el divorcio que ha existido o existe entre los discursos éticos tradicionales y aquellas filosofías que toman el rumbo de lo analítico o de lo puramente científico.

Hasta no hace demasiados años, los pensadores de la ciencia y de sus metodologías renunciaban sistemáticamente a tratar lógicamente o científicamente los problemas de orden estrictamente ético o moral. Parecía una locura querer pasar por el fuero de las ciencias teóricas y de sus lógicas respectivas unos hechos que pertenecían al usufructo exclusivo de meticulosos moralistas, cuya gran barrera teórica estaba en no hacer derivar el deber del ser, es decir, la mítica falacia naturalista.

Sin embargo, parece que los científicos comenzaron a ocuparse de tal tipo de problemas, cuando las conductas morales se desviaron hacia límites insospechados de crueldad con motivo del genocidio nazi o de la utilización bélica de la energía atómica. La estrecha relación entre los avances científicos conseguidos y la utilización cruel y destructiva de tales avances, hacen tomar muy en serio el problema ético y su tratamiento. Comienza, así, a tratarse con interés científico los juicios de valor y las normas, no dejando el tema en manos extracientíficas. Todo ello completado con los últimos estudios sobre los mores humanos en las diferentes culturas y grupos. Surge, de esta forma, el intento de construir una ética científica que

${ }^{3}$ Cf.MUGUERZA, J., La razón sin esperanza, Taurus, Madrid 1986. 
responda a los comportamientos y conductas observables, empleando el método y lenguaje científico y aquellos conocimientos sobre el individuo y la sociedad que nos aportan las ciencias.

Pues bien, estos intentos de hacer compatible la ética con la ciencia y sus metodologías lleva a declarar una especie de decálogo del nuevo ético-científico: no se debe filosofar sobre la ignorancia; se debe partir siempre de la recogida de datos empíricos; plantear enunciados claros y precisos; justificar toda afirmación; preguntar críticamente sobre cada paso que se dé; estar abiertos a una renovación permanente tanto de los contenidos como del lenguaje; y tolerar cualquier hipótesis planteada, aunque podamos someterla a falsación. Hasta aquí la propuesta metodológica que nos plantea M.Bunge para intentar elevar a carácter científico la reflexión ética ${ }^{4}$. Sin embargo, como estima con acierto Toulmin, no podemos sustraernos a la pluralidad de enfoques éticos, ni a las preguntas que nos aportan las distintas posibilidades que se ofrecen desde un método comparativo ${ }^{5}$.

Siguiendo a Edel podemos apreciar que la evaluación y crítica de las teorías éticas supone algo esencial en la construcción de una teoría moral ${ }^{6}$. Los cambios sociales, la falta de un cuerpo acumulado de proposiciones éticas, son causa y consecuencia inevitable del fracaso de desarrollar principios críticos en una teoría ética. Así, los métodos que hoy en día suelen intentar construir tales principios sometidos a crítica son los siguientes: el método analítico, que intenta un análisis de los enunciados morales desde el análisis lógico y desde el sentido común; el método descriptivo, que intenta la descripción de los sentimientos morales como fenómeno; el método causalexplicativo, que intenta centrarse en los efectos de las acciones morales; y el método evaluativo, que intenta analizar, describir y valorar los resultados de las conductas morales de las personas afectadas.

Por tanto, podemos ver que las formas de llevar a cabo una metodología en una ética ambiental son muchas y variadas. La cuestión es que podamos argumentar con cierta claridad acerca del papel que debe desempeñar dicha metodología en un campo esencialmente científico y tecnológico. De hecho, hoy en día se tiende hacia la unidad de métodos, como forma de alcanzar un mejor funcionamiento de la propia teoría ética. Lo que sucede, como advierte Toulmin, es que se hace preciso tabular todo el material acumulado y darle, así, un puesto preeminente a la razón en la teoría ética como dilucidador de los problemas morales y de sus consecuencias.

${ }^{4}$ Cf.BUNGE, M., Ética y ciencia, Siglo XX, Buenos Aires 1972.

${ }_{6}^{5}$ Cf.TOULMIN, S., El puesto de la razón en la ética, Alianza, Madrid 1979.

${ }^{6}$ Cf.EDEL, A., El método en la teoría ética, Tecnos, Madrid 1968. 


\section{EL PROBLEMA DE LA FUNDAMENTACIÓN DE UNA ÉTICA AMBIENTAL}

Pues bien, vistos los modelos metodológicos éticos y vistos los diferentes modelos explicativos del desarrollo moral humano, pasemos ahora a intentar un modelo de fundamentación para la Ecoética, partiendo de la complejidad que acabamos de exponer. En definitiva, intentemos un modelo de fundamentación que sea creíble en el seno de nuestras sociedades plurales y autónomas. Y todo ello desde la pretensión de establecer un procedimiento de toma de decisiones en el ámbito de las ciencias de la vida, partiendo del hecho prioritario de que todos los seres humanos merecen absoluta consideración y respeto, así como el entorno en el que desarrollan su vida ${ }^{7}$.

Pero no nos engañemos. Como nos advierte A.Cortina, el lenguaje tiene sus trampas y tenemos que aquilatar muy bien lo que queremos entender por ética y, por tanto, por eco-ética. El término ética procede del vocablo griego êthos, que viene a significar carácter o forma de vida. Pero esta forma de vida implica dos niveles bien diferenciados: uno atiende a la naturaleza impresa de los hábitos que tenemos, mientras que otro hace referencia al hacerse de cada hombre en la vida. De ahí que los deberes constituyan una parte del objeto de tales saberes, pero no su totalidad. Son un mínimo indispensable para que la propia vida pueda manifestarse en toda su plenitud, es decir, como vida virtuosa o vida buena. Por eso toda ética de los deberes y normas de comportamiento moral será siempre una ética de mínimos, mientras que la ética plena del êthos del hombre tenderá siempre a ser una ética de máximos ${ }^{8}$.

Hoy en día seguimos con las clásicas divisiones entre éticas de bienes y éticas de fines, aunque hablemos en un lenguaje actual de éticas de la justicia y éticas de las virtudes o de la felicidad, además de las llamadas éticas utilitaristas. Dentro de cada una de ellas, a su vez, podemos distinguir aquellas éticas de raigambre más individualistas y aquellas cuya raigambre es preferentemente comunitaria. Pero por intentar una división global, podemos centrarnos en aquellas tres.

Así, por éticas de la justicia entendemos aquellas que recogiendo el legado kantiano, hacen de la persona autónoma el centro de lo moral, por lo que son dichos sujetos los que deben juzgar de un modo racional acerca de la justicia o injusticia de los principios propuestos por una comunidad concreta. Se trata de éticas procedimentales, universalistas, deontológicas y de mínimos, puesto que pretenden universalizar unos cauces formales de procesos de decisión moral desde los cuales poder deducir una serie de normas mínimas de comportamiento colectivo.

Frente a éstas, aparecen las éticas eudemónicas o de virtudes, que partiendo del legado aristotélico y hegeliano tratan de conformar al individuo en el seno de la comunidad donde alcanza su desarrollo pleno como persona. Tratan, así, de formular

\footnotetext{
${ }^{7}$ Vid.CASTRODEZA, C., "Los orígenes biológicos de la virtud", Revista de libros, 27/28 (1999) pp.21-24 / 22-26.

${ }^{8}$ Cf.CORTINA, A., Ética mínima, Tecnos, Madrid 1986.
} 
principios máximos de virtud deducidos de la naturaleza misma del ser humano o de las tradiciones culturales y religiosas de dichas comunidades. En definitiva, podemos decir que estas éticas completan lo intersubjetivo de las éticas de la justicia con su aportación intrasubjetiva.

Finalmente, y frente a las dos anteriores, surgen las llamadas éticas utilitaristas, siguiendo la estela de Hume y Bentham, hoy completadas con el pragmatismo de autores como R.Rorty. Para ellos la moral no es sino un juego de causas y efectos, en el cual debemos tender a maximizar los resultados favorables tanto para el individuo como para la sociedad. Por tanto, el criterio moral último será el beneficio real que aporte una decisión u otra, sin criterios previos ni principios absolutos. A estas corrientes podemos asimilar en lo fundamental el sociologismo moral o, igualmente, el biologicismo moral, donde el criterio último será o la lógica social o la propia lógica de la biología.

Pasemos, así, a desarrollar un modelo de fundamentación siguiendo la estela de X.Zubiri, autor adecuado para un planteamiento ético del mundo de las ciencias de la vida, intentando conciliar las tres tendencias anteriormente expuestas ${ }^{9}$. Pues bien, Zubiri parte de que la realidad moral es constitutivamente humana; no se trata de un ideal a alcanzar, sino de una verdadera forzosidad o exigidad del constructo psicoorgánico que es el hombre. El hombre tiene necesidad de apropiarse de unas posibilidades que le plantea la realidad, lo que le conduce a justificarse ante el medio, es decir, a dar cuenta y razón de la realidad. Por tanto, dentro de ciertos límites, el hombre sí puede trazar su área de justificación: al hombre que ejecuta un acto se le pueden pedir cuentas de él. Y ese dar cuenta del acto en sí supone dar razón del mismo, es decir, indicar las posibilidades de dicho acto. Es lo que Zubiri denomina dimensión de preferencia, que no es otra cosa que la justificación de unas posibilidades frente a otras.

Ahora bien, a dicha justificación preferencial el hombre no llega sin más, sino que se siente impelido por unas tendencias que resultan ser inconclusas. Aquí podrían entrar diversas teorías ya expuestas: así, el utilitarismo pragmático resolvería esta cuestión por medio de la presión de los grupos sociales sobre las preferencias del hombre; mientras que las teorías de los principios de justicia intentarían deducir un imperativo condicional y categórico en el ámbito de un saber puro, por lo que las acciones del hombre estarían justificadas cuando realizara su deber. Zubiri, sin embargo, presupone un subjectum o razonamiento consciente que es previo y ante el cual la valoración es objetiva. Y si los valores son objetivos y valiosos es porque las cosas son valiosas para una realidad que es la del hombre. Por tanto, siguiendo a Scheler, entiende que el bien no es soporte de valores sino su raíz.

El hombre, nos dice Zubiri, al justificar sus actos va describiendo su propio ámbito de actuación moral; por lo que el ser humano se va apropiando de ciertas

${ }^{9}$ Cf.ZUBIRI, X., Sobre el hombre, Alianza, Madrid 1986. A Zubiri le han seguido autores como P.Laín Entralgo o D.Gracia. 
posibilidades que formarán su propia realidad como animal moral. Ahora bien, ¿qué es lo que hace el hombre con su moralidad? El ser humano, nos aclara Zubiri, lanzado sobre sí se encuentra ante sí mismo como aquella realidad desde la que tiene que resolver su vida. De tal forma que el hombre debe resolver la situación en la que se encuentra, puesto que no puede quedarse en ella sino que tiene que determinar cómo quiere ser hombre efectivamente. Por tanto, el hombre, así constituido, aparece como el animal que busca constitutivamente la felicidad o animal beatificable. Pero esta felicidad no es sólo sentirse bien o pleno, sino sentirse realmente bien, o lo que es lo mismo, estar bien en la realidad; de ahí que seamos, igualmente, animales de realidades. $\mathrm{Y}$ en esa realidad que nos constituye se encuentra, no sólo su ser individualizado, sino su ser social y ambiental.

De todo esto podemos concluir con Zubiri que "sólo tenemos moralidad en cuanto contamos con felicidad". De hecho, cuando hablamos de deber no estamos ante una posibilidad más, sino aquella que es más conducente a la felicidad del hombre. El deber, por tanto, no se contrapone a la felicidad sino que el hombre está ligado constitutivamente en cada situación a ser feliz. Pero esto no supone confundir el deber con la felicidad, sino que son las posibilidades las que nos ordenan hacia la felicidad. Es más, lo propio del deber no es ser impuesto, sino ser apropiado; lo que supone que el hombre se encuentra debitoriamente o impelido respecto de su propia realidad. No caben, por tanto, normas impuestas desde fuera, sino la puesta en marcha de una inteligencia que dé lugar a una razón práctica que uno se va haciendo, es decir, al sentido moral. De hecho, el hombre se configura abierto desde sus posibilidades hacia su propia perfección, de lo cual es responsable. Por eso la sanción no es de ningún modo un castigo, sino que el hombre consiga ser plenamente lo que radicalmente ha querido ser.

El problema es que la realidad ante la que el hombre responde dando cuenta de ella es fundamentalmente social e histórica. Por eso Zubiri exige una adecuación de la situación concreta del ser humano dentro de una sociedad en un tiempo histórico concreto. Esto implica un cambio real y efectivo de las posibilidades de perfección que el hombre tiene radicalmente dentro de sí, en tanto que compuesto o constructo psico-físico. El hombre, así, se ve obligado a hacerse cargo de la realidad de una forma responsable, cargando con la incertidumbre moral que supone la indeterminación de las posibilidades que le pueden llevar hasta su perfección. Éste es su drama, que tan lúcidamente supieron ver y expresar las corrientes existencialistas: el paso de lo puramente biológico a lo radicalmente humano.

Pues bien, todo esto nos lleva a contemplar la ecoética desde aquellos principios que, deducidos por la razón, se nos muestran como posibilitantes de nuestra propia perfección y felicidad. En definitiva, siguiendo a Ortega, podemos concluir afirmando que el hombre aparece como un ser moral y libre, con un quehacer histórico vital que es dar cuenta de la realidad ${ }^{10}$. Surge, así, el animal valorativo, es decir, el ser capaz de

\footnotetext{
${ }^{10}$ Cf.ORTEGA Y GASSET, J., El hombre y la gente, Espasa-Calpe, Madrid 1972.
} 
valorar de forma diferente las distintas posibilidades que tiene ante sí para conformarse en la realidad desde un sistema de valores dado. Y esa realidad de la que debemos dar cuenta se compone, no sólo de nuestra vida individualmente considerada, sino de nuestra vida vivida y desarrollada en un entorno que la conforma. Por tanto, si hay ética de la vida, será una ética de nuestra vida humana y de su entorno ambiental donde se desarrolla y se construye, no como una dualidad externa y objetivable, sino como una unidad intrínseca y subjetivable.

\section{POSIBILIDADES DE UNA ÉTICA AMBIENTAL O ECOÉTICA}

Si tomamos en serio lo anteriormente expuesto, podríamos definir la Ecoética como el estudio sistemático de la conducta humana en el área de las ciencias ambientales, a la luz de los principios y valores éticos y normativos. Esta Ecoética deberá construirse desde los factores que nuestro mundo actual la impelen y la exigen: avances incesantes en el campo de las ciencias y de las tecnologías aplicadas, que tienen como referente las actuaciones sobre el medio; los cambios profundos en nuestra relación con la naturaleza, pasando de ser considerada nuestra propiedad a ser el lugar donde debemos construir nuestra propia vida; la secularización de los principios ético-innatistas, que nos hacen construir principios universales basados en los mínimos comunes morales que diferentes culturas podemos compartir; y, finalmente, la alarmante degradación del medio en el que vivimos, o lo que es lo mismo, nuestro olvido de la physis, ante la que durante mucho tiempo hemos tomado la postura, como advierte Bilbeny, del idiota moral, es decir, la moral de la excusa o de la indiferencia como única forma de justificar lo acaecido ${ }^{11}$.

Esta ecoética deberá dirigirse, al menos, a cuatro ámbitos de aplicación: en primer lugar, por su impacto, a la actividad productiva del ser humano sobre la naturaleza, actividad incesante y altamente tecnológica en nuestros días, lo que la hace mucho más eficiente y, en algunos casos, más devastadora; en segundo lugar, se dirigirá hacia la actividad investigadora en todos aquellos campos que afecten directa o indirectamente al medio ambiente; y, por último, se dirigirá de manera urgente hacia la prevención de actuaciones que, no sólo la ética, sino el Derecho debería regular y aplicar el principio de precaución antes de provocar el deterioro irreversible de dicho medio $^{12}$.

Estos tres ámbitos de desarrollo ecoético, nos conducen a dos tendencias que la ecoética debería afrontar de manera urgente: la introducción de los principios ecoéticos en las deontologías profesionales que inciden de manera directa en el

${ }^{11}$ Cf. BILBENY, R., Ecoética. Ética del medio ambiente, Edit.Aresta, Barcelona 2010.

${ }^{12}$ Vid.VELAYOS, C., La dimensión moral del ambiente natural. ¿Necesitamos una nueva ética?, Granada 1996; Id. Tomarse en serio la naturaleza. Ética ambiental en perspectiva multidisciplinar, Madrid 2004; Id. Ética y cambio climático, Bilbao 2008. 
cuidado o devastación del medio (ambientalistas, ingenieros, arquitectos, químicos, biólogos...); y la introducción de los principios ecoéticos en las legislaciones sectoriales sobre medio ambiente que a nivel nacional o internacional tratan de proteger y paliar el daño medioambiental. Un ejemplo de esto último lo tenemos en la Ley 42/2007 del Patrimonio Natural y de la Biodiversidad, que en su preámbulo desarrolla los principios básicos de una ética ambiental, de la que es reflejo la normativa desarrollada.

De esta manera, podemos deducir ya una serie de principios ecoéticos que actúen y se apliquen a las diferentes facetas que hemos comentado. En primer lugar, el ya mencionado principio de precaución en toda intervención que afecte a espacios naturales y sin cuya aplicación podrían derivarse actuaciones altamente lesivas para el medio ambiente. En segundo lugar, la prevalencia de la protección ambiental sobre cualquier elemento productivo o de ordenación del territorio, de tal manera que las normas que regulen dichas actuaciones exijan el cumplimiento de protocolos ambientales claramente definidos. En tercer lugar, impulsar los procesos de sostenibilidad medioambiental en cualquier desarrollo industrial o territorial, exigiendo como preceptivos informes de impacto ambiental desde la exigencia de cuidar del entorno como procuramos cuidar de nuestra propia vida. En cuarto lugar, la integración del principio de conservación, mejora y restauración de la biodiversidad, como requisito previo para la aprobación de cualquier proyecto industrial o territorial. En quinto lugar, la aplicación de políticas públicas de participación ciudadana en el diseño de las mismas, dado que toda actuación ambiental supone una directa actuación sobre la vida humana, no algo ajeno o añadido a la misma. Y, por último, aunque no por ello menos importante, entender el patrimonio natural como parte de la función social integrada, es decir, alejarse de concepciones dualistas del medio como elemento extrínseco a la vida de los seres humanos, y pasar a entenderlo como parte consustancial de nuestra existencia sobre el planeta.

Sólo desde la aplicación práctica de estos principios ecoéticos, podremos olvidarnos poco a poco de nuestra rémora de siglos entendiendo que la naturaleza nos pertenece y como poseedores de la misma nos enfrentamos con ella hasta sacarle el máximo partido; olvidarnos de que los recursos naturales son renovables por definición y, por tanto, no se extinguirán nuca; olvidarnos de que la naturaleza está al servicio del ser humano, sin percatarnos que en ese servicio ponemos a nuestro servicio la vida de seres humanos como nosotros; y olvidarnos, al fin, de que la meta de nuestra capacidad tecnológica y científica no es aquella que decíamos al comienzo de esta reflexión, a saber, extenuar nuestro entorno hasta que nos dé todo aquello de que sea capaz, sino precisamente aplicarla al servicio de nuestra supervivencia como especie. Y, por cierto, especie que como el resto de seres vivos del planeta, depende de su medio e interactúa con él a sabiendas de que forma parte del mismo. 


\section{BIBLIOGRAFÍA}

BILBENY, R. (2010). Ecoética. Ética del medio ambiente, Edit.Aresta, Barcelona.

BUNGE, M. (1972). Ética y ciencia, Siglo XX, Buenos Aires.

CASTRODEZA, C. (1999). Los orígenes biológicos de la virtud, Revista de libros, 27/28 pp.21-24 / 22-26.

CORTINA, A. (2009). Las fronteras de la persona. El valor de los animales, la dignidad de la persona, Madrid.

CORTINA, A. (1986). Ética mínima, Tecnos, Madrid.

EDEL, A. (1968). El método en la teoría ética, Tecnos, Madrid.

GAFO, J. (1999). Ecoética, en 10 palabras clave en Ecologia, Estéis.

GÓMEZ HERAS, J.M. (1997). Ética del medio ambiente. Problrema, perspectiva, historia, Madrid.

GRACIA, D. (1989). Fundamentos de Bioética, Madrid.

KÜNG, H. (1999). Una ética mundial para la economía y la política, Madrid.

LEOPOLD, A. (2000). Una ética de la tierra, Madrid.

MUGUERZA, J. (1986). La razón sin esperanza, Taurus, Madrid.

ORTEGA Y GASSET, J. (1972). El hombre y la gente, Espasa-Calpe, Madrid.

POTTER, V.R. (1998). Global Bioethics, Michigan.

RUBIO CARRACEDO, J. (1987). El hombre y la ética, Anthropos, Barcelona.

SINGER, P. (1984). Ética práctica, Barcelona.

TAYLOR, W. (1986). Respect for Nature: a theory of enviroment ethics, Princeton.

TOULMIN, S. (1979). El puesto de la razón en la ética, Alianza, Madrid.

VELAYOS, C. (1996). La dimensión moral del ambiente natural. ¿Necesitamos una nueva ética?, Granada

VELAYOS, C. (2004). Tomarse en serio la naturaleza. Ética ambiental en perspectiva multidisciplinar, Madrid.

VELAYOS, C. (2008). Ética y cambio climático, Bilbao.

ZUBIRI, X. (1986). Sobre el hombre, Alianza, Madrid. 